\title{
Geochemical and mineralogical investigation of domestic archaeological soil features at the Tiel-Passewaaij site, The Netherlands
}

\author{
S. Oonk ${ }^{\text {a,* }}$, C.P. Slomp ${ }^{\text {b }}$, D.J. Huisman ${ }^{\text {c }}$, S.P. Vriend ${ }^{\text {b }}$ \\ a Institute for Geo- and Bioarchaeology, Faculty of Earth and Life Sciences, VU University Amsterdam, De Boelelaan 1085, 1081 HV Amsterdam, The Netherlands \\ ${ }^{\mathrm{b}}$ Faculty of Geosciences, Department of Earth Sciences-Geochemistry, Utrecht University, P.O. Box 80021, 3508 TA Utrecht, The Netherlands \\ c RACM, National Service for Archaeology, Cultural Landscape and Built Heritage, P.O. Box 1600, 3800 BP Amersfoort, The Netherlands
}

\section{A R T I C L E I N F O}

\section{Article history:}

Received 23 January 2008

Accepted 16 June 2008

Available online $\mathrm{xxxx}$

\section{Keywords:}

Soil features

Phosphorus

Chemical extractions

Mineralogy

Archaeology

\begin{abstract}
A B S T R A C T
Archaeological soil features can be defined as areas of staining in ancient cultural soil horizons and are frequently used in surveys to locate sites and activity areas. Visual observation of these features, however, provides only limited information on their origin and the processes leading to their formation and this limits site interpretation. This paper presents the results of geochemical and mineralogical analyses of domestic archaeological soil features in order to assess their composition, formation pathway and origin. The greenish soil features studied here belong to a house plan from a Roman farmhouse located at the Tiel-Passewaaij site in the Netherlands. The soils were investigated using a range of techniques, including X-ray Fluorescence (XRF) spectroscopy, sequential soil extractions, Fourier-transformed infrared (FT-IR) spectroscopy, X-ray Diffraction (XRD) and microprobe analysis. The results indicate that the studied soil features can chemically be distinguished from off-site soils e.g. based on their phosphate and carbonate content. Mineralogical analysis of aggregate samples from soil features further reveal that quartz and feldspar minerals are coated with $\mathrm{Ca}-\mathrm{Fe}-\mathrm{P}$ phases that closely resemble anapaite and mitridatite mineral forms. The formation of these mineral phases probably resulted from periodic reductive dissolution of Fe-oxide phases and subsequent precipitation of $\mathrm{Fe}-\mathrm{P}$ phases, with inclusion of $\mathrm{Ca}$ from anthropogenic carbonates or groundwater. The combined presence of (Ca)-carbonates, P-phases and some anthropogenic trace elements $(\mathrm{Cu}, \mathrm{Zn})$ suggests that the greenish soil features stem from manure inputs.
\end{abstract}

(c) 2008 Elsevier B.V. All rights reserved.

\section{Introduction}

Among the visible remnants of human occupation in Northern Europe, soil features or areas of soil staining are most abundant and their presence is of great importance for archaeological prospection and delineation of activity areas within exposed sites (Dekker and de Weerd, 1973). Their importance can be seen from the fact that these features are immobile (Renfrew and Bahn, 1991; Huisman, 2006) and in primary context, which makes them, in general, more suitable for the interpretation of sites than other artifacts. Soil features originate from buried organic and mineral materials, which stem from domestic structures (e.g. farms, barns, fences), dumps, hearths or burials. Chemically and mineralogically soil features are thus likely to differ in composition from the parent soil material and they often can be recognized by anomalies in soil colour.

Soil features are formed by pedogenesis acting on anthropogenic materials and a wide variety of (bio)geochemical processes are involved in their formation, including bacterial breakdown of the organic material, as well as adsorption, precipitation, humification and

\footnotetext{
* Corresponding author. Tel.: +31 205987295; fax: +31 205987155

E-mail address: stijn.oonk@falw.vu.nl (S. Oonk).
}

mineralization. Apart from degraded organic materials, anthropogenic mineral inputs are also likely to play a significant role in feature formation. In addition, $\mathrm{Al}, \mathrm{Fe}$ and Mn-oxides are essential because of their abundance in most soils (Stipp et al., 2002) and reactivity towards many (in)organic soil constituents (Fortin et al., 1993; Sugita and Marumo, 1996; Tessier et al., 1996). Thus, soil feature formation is likely to be affected by the oxidation state of metals in soils, the mineral forms in which these metals occur (Fontes and Weed, 1996), their crystallinity and degree of cementation (Sugita and Marumo, 1996). Due to the constant addition of anthropogenic elements to the soil during occupation, mineral precipitation may also be important in feature formation. This is in accordance with observations of contaminated soils and landfill leachate plumes (see e.g. Loch et al., 1981; Gong and Donahoe, 1997; Christensen et al., 2001).

Although archaeological soil features can be invaluable in aiding site interpretation, additional information is often necessary to understand the origin of a feature and, subsequently, the former space use. Multi-element analysis of soils has been applied to this purpose (Griffith, 1981; Middleton and Price, 1996; Parnell et al., 2002; Knudson et al., 2004; Sullivan and Kealhofer, 2004; Terry et al., 2004; Wells, 2004; Cook et al., 2005; Wilson et al., 2008). Results from these studies indicate that activity areas often can be chemically 
detected and interpreted, but success depends heavily on the analytical methods applied, data handling, post-depositional pedogenic processes and available ethnoarchaeological information.

Detection and delineation of archaeological structures, such as houses, barns and farms, is commonly based on the patterning of postholes and hearths. Apart from these features, diffuse greenish yellow or reddish soil colourizations have been observed within and around such structures (Dekker and de Weerd, 1973; Steenbeek, 1983, 1984; Hessing and Steenbeek, 1992). These features are clearly unrelated to digging activities in the past (e.g. excavation of post-holes or trenches), but are believed to result from phosphate rich manure inputs and may be indicative of livestock-holding. Conclusive evidence on the origin and formation of these features however has not been reported yet.

In this study, a multidisciplinary approach is used to acquire knowledge on the chemical and mineralogical composition of greenish soil features in order to determine their composition and elucidate chemical pathways that lead to their formation. In addition, this research tests the archaeological hypothesis that the studied soil features are indicative of stables or places where livestock was held and hence that interpretation of former space use by means of such features is feasible.

\section{Materials and methods}

\subsection{Study area}

A house plan of a Roman farmhouse (TH14), including four ellipsoidal soil features (S125, S147, S14 and S158) was investigated (Fig. 1). The house plan is part of the Tiel-Passewaaij settlement and is located on the bank of an ancient river channel of the Waal river in the central river area of the Netherlands. The house plan measured 30 by $6 \mathrm{~m}$ and probably consisted of two compartments; a living quarter and a stable (Heeren, 2006; Kooijmans et al., 2005). Archaeological evidence further indicates that TH14 was used during two successive periods between 100 and 160 A.D.

Being part of a river floodplain, the study area is hydrologically active and exhibits variable water tables. The soils consist of alkaline (pH 7.0-8.0) calcareous sandy clays (Huisman, 2006).

\subsection{Sampling and analytical methods}

Using grid sampling ( $50 \mathrm{~cm}$ by $50 \mathrm{~cm}$ grid), approximately $15,10 \mathrm{~g}$ samples of each soil feature were collected from the exposed ancient cultural horizon. To study natural soil characteristics 10 off-site locations in close proximity of the house plan were sampled as well. Non-stained areas within the house plan were not sampled, because delineation of the soil features was unclear. In addition, several greenish mineral aggregates (approximately $0.25 \mathrm{~g}$ ) in the soil features were sampled for detailed chemical and mineralogical study by FT-IR and SEM-EDX. These samples were air dried and stored in plastic vials. All other samples were freeze-dried, crushed and homogenized by mortar and pestle, sieved through a $2 \mathrm{~mm}$ sieve and stored in plastic vials.

\subsubsection{Chemical analysis}

Total element content of the soil samples was measured by XRF analysis (Philips PW 1450 sequential X-ray spectrometer) using waxpressed tablets. To assess the geochemistry of the soil features in more detail we also aimed our methodology on easily to moderately soluble components and phases associated with Fe-(oxy)(hydr)oxides. Concentrations for moderately soluble elements, including total inorganic $\mathrm{P}$ were obtained using weak $\mathrm{HCl}$ soil extractions and inductively coupled plasma optical emission spectroscopy (ICP-OES). One gram $( \pm 0.025 \mathrm{~g})$ of soil and $25 \mathrm{ml}$ of $1 \mathrm{M} \mathrm{HCl}$ were mechanically shaken for $24 \mathrm{~h}$ at room temperature. The mixture was centrifuged for $10 \mathrm{~min}$ at $3000 \mathrm{rpm}(1411 \mathrm{~g})$ and the supernatant was filtered through Whatmann cellulose filters ( $0.45 \mu \mathrm{m}$ pore size). The extracts were diluted with $5 \% \mathrm{HNO}_{3}$ and stored in PVC tubes at $7{ }^{\circ} \mathrm{C}$ prior to analysis.

A random selection of 10 samples from S125 and 10 off-site samples were also sequentially extracted with (I) magnesium chloride $\left(\mathrm{MgCl}_{2}\right)$, (II) citrate-ascorbate-bicarbonate (CAB), (III) citrate-dithionite-bicarbonate (CDB) and (IV) $\mathrm{HCl}$. In this approach (partly adapted from Ruttenberg, 1992; Slomp et al., 1996; Hyacinthe and Van Cappellen, 2004) $\mathrm{MgCl}_{2}$ is assumed to displace exchangeable or loosely adsorbed components (Ruttenberg, 1992; Parkman et al., 1996). Non-crystalline metal oxides are selectively dissolved by ascorbic acid and chelated by citrate (step II) (Larsen and Postma, 2001). Step III (CDB) dissolves remaining reactive metal oxides (i.e. $\mathrm{Al}^{3+}, \mathrm{Fe}^{3+}$ or $\mathrm{Mn}^{2+}$-phases, in crystalline arrangement) by means of reduction by dithionite and subsequent chelation by citrate (Ruttenberg, 1992). Step IV (HCl) attacks all residual inorganic phases, such as carbonates, unreactive (hydr)oxides, phosphates and sulfides, while leaving the more resistant silicates largely intact. Specifications of our extraction steps are as follows: (step I) $25 \mathrm{ml}$ of a $1 \mathrm{M}$ aqueous solution of $\mathrm{MgCl}_{2}(\mathrm{pH}=8)$ was mixed with $1 \mathrm{~g}$ of soil and shaken at room temperature for $2 \mathrm{~h}$ (Ruttenberg, 1992). Subsequently,
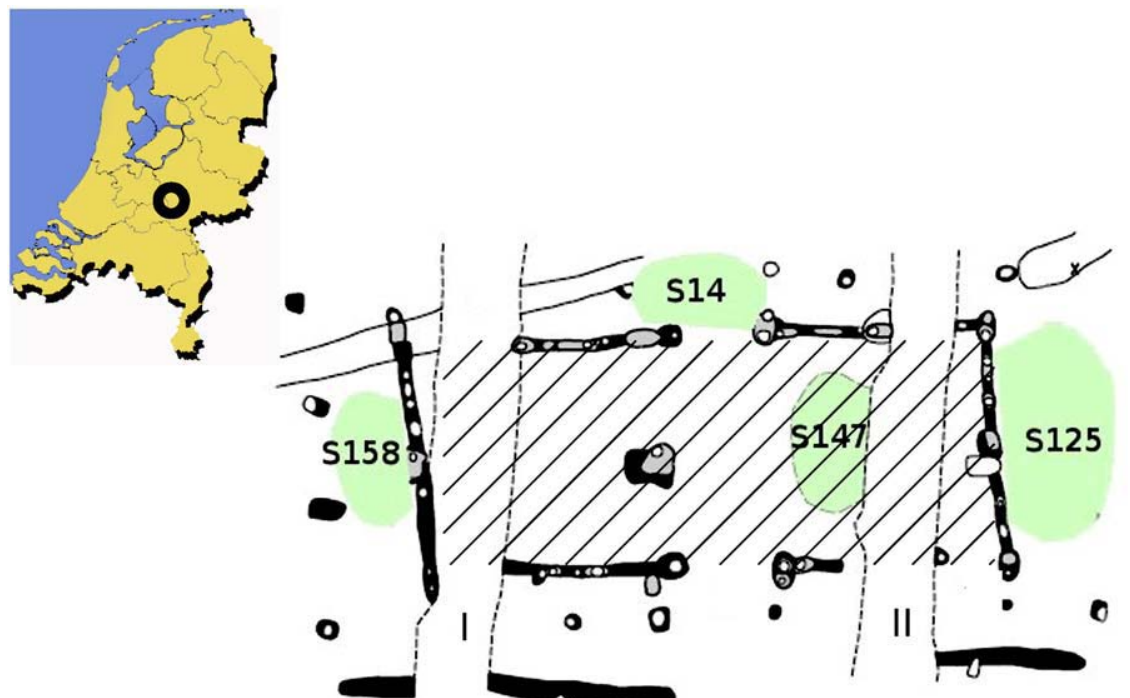

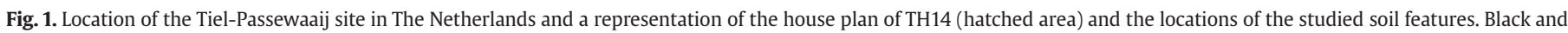
gray areas represent post-holes and ancient ditches. Modern ditches are indicated by I and II. 
the mixture was centrifuged at $3000 \mathrm{rpm}(1411 \mathrm{~g})$ for $10 \mathrm{~min}$ and then the supernatant was filtered $(0.45 \mu \mathrm{m}$ pore size $)$ and collected in PVC tubes. (step II) A $25 \mathrm{ml}$ volume of the CAB solution was added to the wet sediment and shaken for $24 \mathrm{~h}$ at room temperature. After subsequent sample handling (equal to step I) the sediment was washed with $1 \mathrm{M}$ $\mathrm{MgCl}_{2}$ for $2 \mathrm{~h}$ to remove re-adsorbed constituents. The CAB extraction solution was a deoxygenated buffered solution $(\mathrm{pH} \approx 7.5)$ of Na-citrate $(50 \mathrm{~g} / \mathrm{l}), \mathrm{NaHCO}_{3}(50 \mathrm{~g} / \mathrm{l})$ and $10 \mathrm{~g} / \mathrm{l}$ of $\mathrm{L}(+)$ ascorbic acid $\left(\mathrm{C}_{6} \mathrm{H}_{8} \mathrm{O}_{6}\right)$. (step III) To the remaining wet sediment $25 \mathrm{ml}$ of the $\mathrm{CDB}$ solution was added and shaken at room temperature for $8 \mathrm{~h}$. The CDB extractant consisted of $0.30 \mathrm{M}$ Na-citrate, $1.0 \mathrm{M} \mathrm{NaHCO}_{3}(\mathrm{pH} \approx 7.5)$ and Na-dithionite $(0.025 \mathrm{~g} /$ $\mathrm{ml}$ ). Additional sample handling and washing procedures were equal to steps I and II. (step IV) The remaining wet sediment was mixed with $25 \mathrm{ml}$ of $1 \mathrm{M} \mathrm{HCl}$, shaken for $24 \mathrm{~h}$ at room temperature and subsequently handled as described in step I. All extracts were stored at $7{ }^{\circ} \mathrm{C}$ for several days. Prior to ICP-OES multi-element analysis the samples were diluted 5 times with deionized (milli-Q) water (CAB and $\mathrm{HCl}$ extracts) or $1 \mathrm{M} \mathrm{HNO}_{3}$ $\left(\mathrm{MgCl}_{2}\right.$ and $\mathrm{CDB}$ extracts). To avoid matrix effects, calibration standards were prepared in the respective extraction solutions and all four sample batches were analyzed separately. All extracts were analyzed on a PerkinElmer Optima 3000 ICP-OES spectrometer.

\subsubsection{Mineralogical analysis}

For XRD analysis 5 aggregate samples from S125 and 5 off-site samples were randomly selected and sieved $(<63 \mu \mathrm{m})$ in order to minimize signals from quartz. A suspension of about $1 \mathrm{~g}$ of sediment and $25 \mathrm{ml}$ of deionized water (milli-Q) was vortexed for $1 \mathrm{~min}$, after which $1 \mathrm{ml}$ was pipetted onto a glass slide. The sediment was allowed to dry in an oven at $25^{\circ} \mathrm{C}$ for $2 \mathrm{~h}$. The sediment coated glass slide was mounted on a vertical sample holder by means of air suction through a series of vacuum holes. Diffraction patterns were recorded on a Bruker B8 Discover diffractometer using a $2 \theta-\theta$ geometry. The wavelength was $1.5418 \AA(\mathrm{Cu} \mathrm{K} \alpha)$ and the samples were scanned from 15 to $35^{\circ} 2 \theta$ with a step size of 0.040 counting for $25 \mathrm{~s}$ per step.

A selection of aggregate samples from all features and off-site samples were used for FT-IR spectroscopy analysis. Spectra were obtained from soils pressed into $\mathrm{KBr}$ pellets $(1 \% \mathrm{w} / \mathrm{w})$ and were analyzed using a PerkinElmer 2000 FT-IR spectrometer. To avoid undesired adsorption by water, excess water was removed in an oven at $25^{\circ} \mathrm{C}$ for $24 \mathrm{~h}$ prior to sample preparation.

Compositional measurements (energy dispersive X-ray analysis, EDX) and electron microscopy (SEM) was performed on a JEOL JXA8600 microprobe. Aggregate samples from S125 were freeze-dried, gently crushed, embedded in resin, and carbon coated. The acceleration voltage was set at $15 \mathrm{keV}$ and the beam current at $20 \mathrm{nA}$.

\section{Results}

\subsection{General geochemical characterization}

Some descriptive statistics for total element concentrations (XRF data) in the feature- and off-site soils are given in Table 1. In general, soil chemistry is very similar for all studied features, except for S158 which, on average has the lowest element concentrations. Off-site samples display two distinct populations (hereafter called BG-1 and BG-2) for Si, Ca, P and most trace elements. Most apparent differences between feature- and off-site samples are observed for BG-2. Twotailed student $t$-tests for the differences in total element concentrations between the feature- and BG-2 samples show that all features can be chemically distinguished from the off-site samples. Most apparent differences are found for $\mathrm{Ca}, \mathrm{Cu}, \mathrm{P}$ and $\mathrm{Zn}$. Therefore, in this study, we consider these elements as anthropogenic, whilst other measured elements are regarded geogenic. Chemical differences are also shown between soil features and are most apparent for $\mathrm{Al}, \mathrm{Fe}, \mathrm{Ti}$ and $\mathrm{K}$, while S158 is the only feature that can be distinguished based on P levels. Soil features S14 and S147 can additionally be distinguished

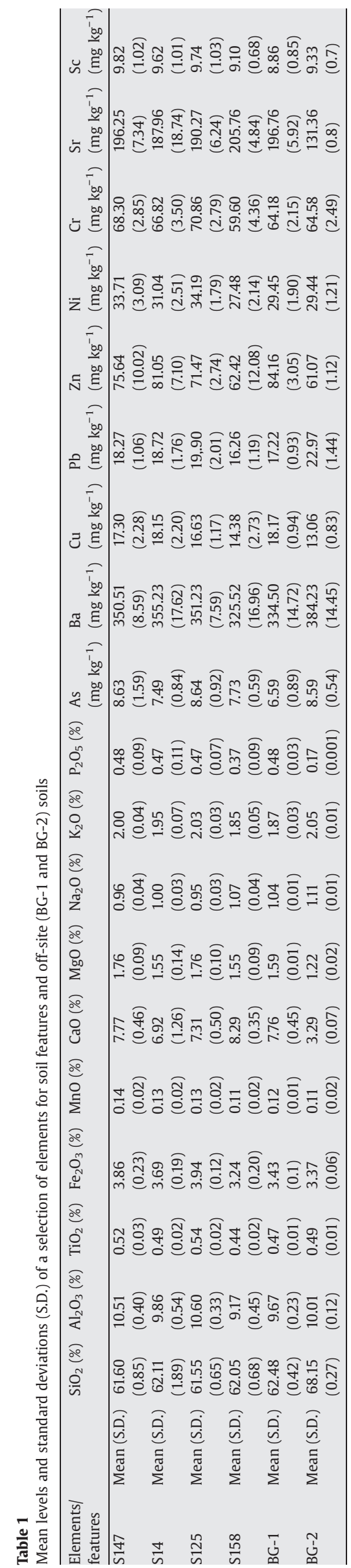



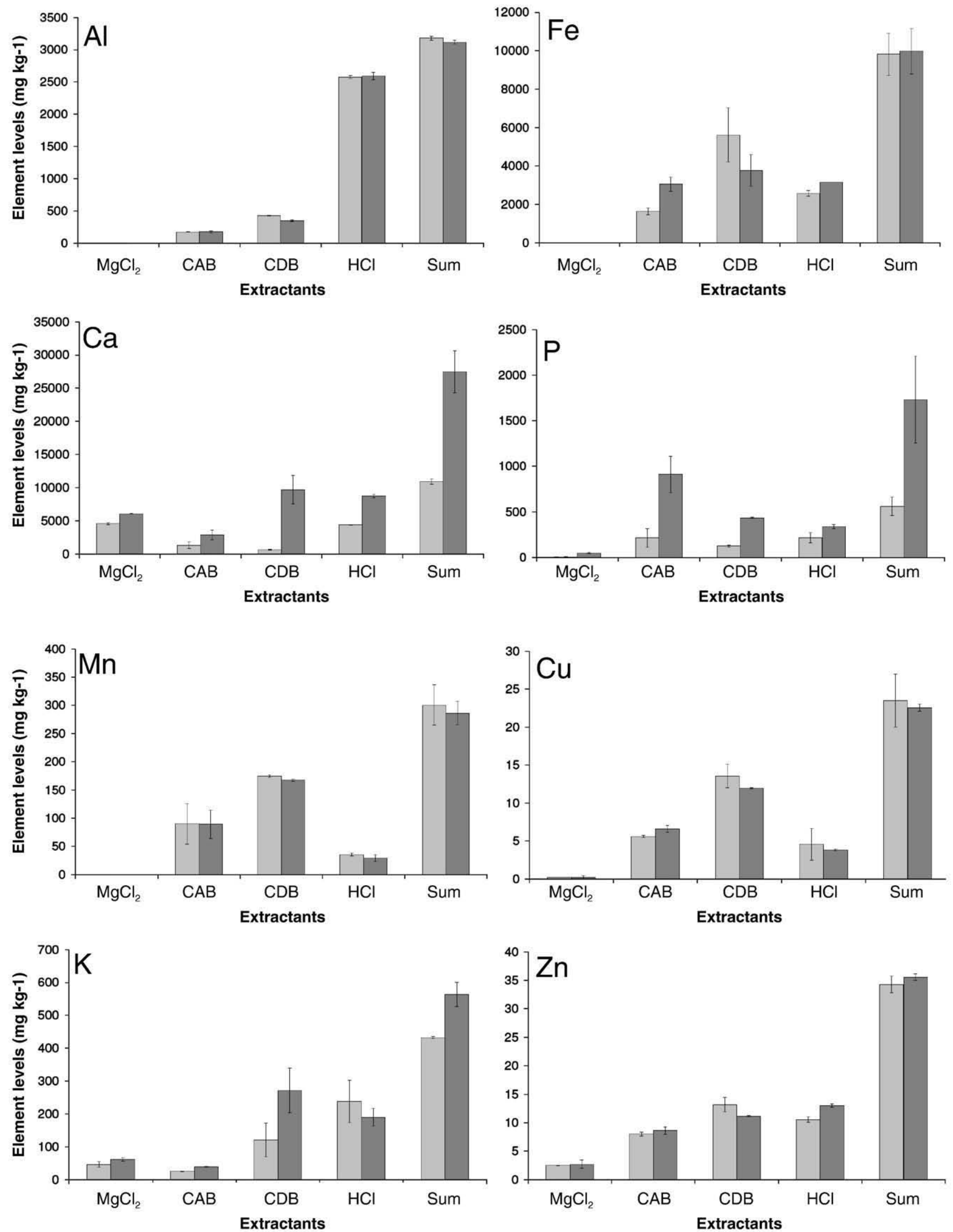

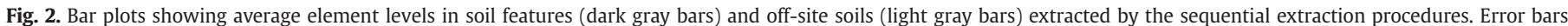
represent the standard error of the means. 
based on their $\mathrm{Ca}, \mathrm{K}, \mathrm{Pb}$ and $\mathrm{Cr}$ content. Phosphorus and $\mathrm{Si}$ concentrations were found to be equal in most soil features. Element distributions within the features are homogeneous, except for Mn, P and some trace metals (i.e. As, $\mathrm{Cu}, \mathrm{Zn}$ and $\mathrm{Sc}$ ), which show relatively high variation. Element variation is generally lower for off-site locations than for features.

\subsection{Geochemistry of sequentially extracted soil phases}

The results of the sequential extraction experiments for a selection of elements ( $\mathrm{Al}, \mathrm{Ca}, \mathrm{Cu}, \mathrm{Fe}, \mathrm{K}, \mathrm{Mn}, \mathrm{P}$ and $\mathrm{Zn}$ ) from S125 and BG-2 are shown

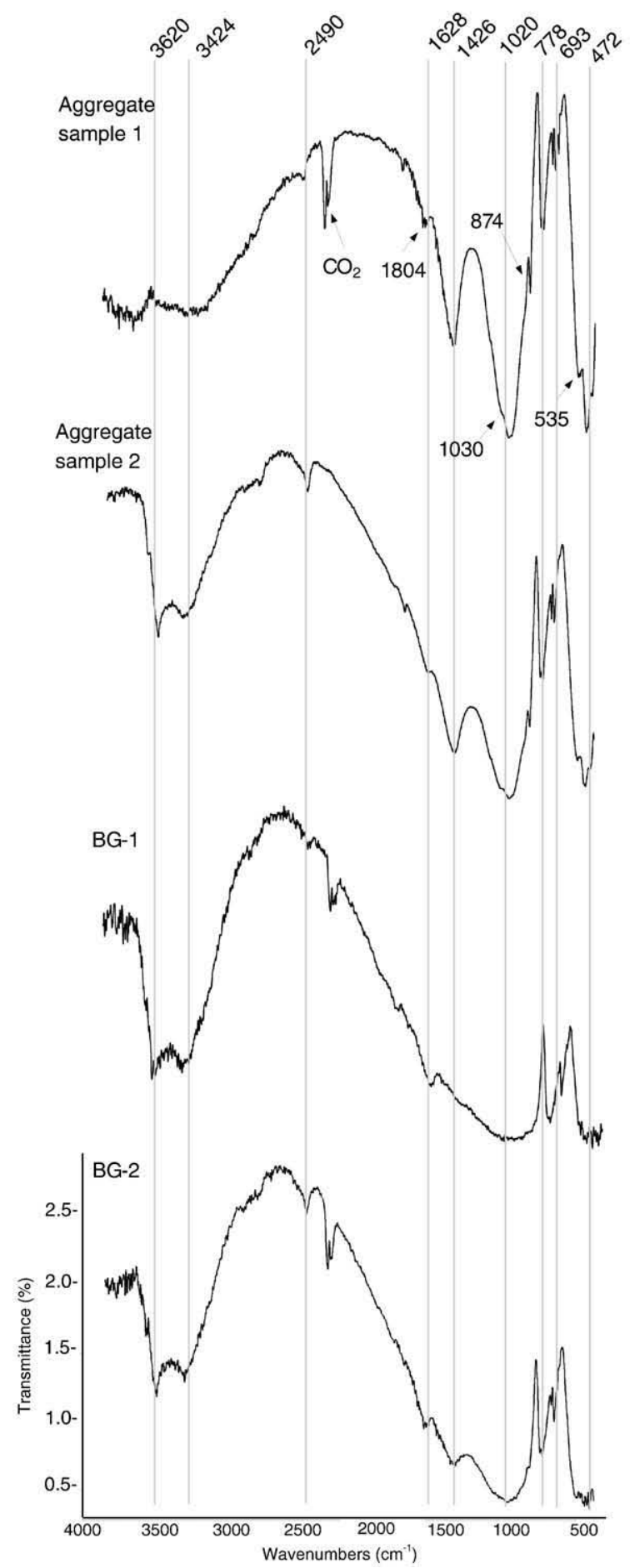

in Fig. 2. The extraction efficiency (ICP-OES vs. XRF data) is relatively low (max. 30\%) for most elements and is in accordance with the aim of our approach to extract moderately soluble soil components.

\subsubsection{Pedogenic elements}

Aluminium distribution over the extracted soil phases is largely identical for S125 and BG-2 soils. Residual inorganic Al accounts for about $80 \%$ of the total sequentially extracted Al. Only $5-10 \%$ is held by reducible phases, and exchangeable $\mathrm{Al}$ levels are below detection limits.

In S125 soils, residual, crystalline and non-crystalline Fe-phases account for about $30 \%$ of total sequentially extracted Fe each. In BG-2

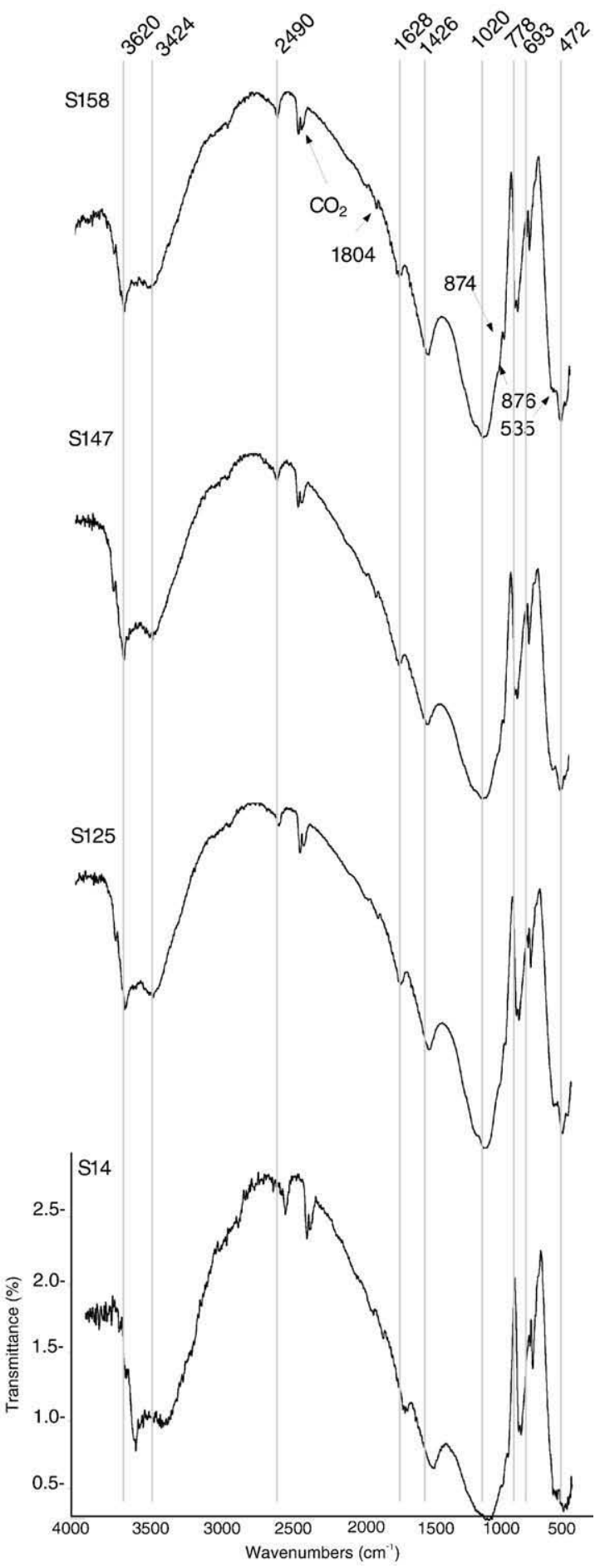

Fig. 3. FT-IR spectra from the studied feature soils, off-site samples and aggregates. The vertical lines and corresponding wavenumbers display the most prominent vibrations. 
soils, Fe is prevalently in the form of crystalline $\mathrm{Fe}^{3+}$-phases (on average $57 \%$ of the total), with non-crystalline- and residual phases making up about $16 \%$ and 26\% respectively. Exchangeable Fe levels are below detection limits.

Distribution patterns for Mn over the extracted soil phases are identical for $\mathrm{S} 125$ and BG-2 soils. On average, 30\% and 58\% of the total sequentially extracted $\mathrm{Mn}$ is present as non-crystalline- and crystalline Mn-phases respectively. About $10 \%$ of the total is of residual nature, whilst exchangeable Mn shows very little contribution to total Mn levels ( $<1 \%)$.

Calcium and $\mathrm{K}$ are present in various soil phases. The results for S125 suggest that $\mathrm{K}$ is predominantly held by crystalline reducibleand residual phases, accounting for about $50 \%$ and $30 \%$ each. Opposite findings are obtained regarding BG-2 soils; i.e., in these soils 55\% of total sequentially extracted $\mathrm{K}$ is associated with residual phases and $28 \%$ with crystalline reducible phases. Exchangeable $\mathrm{K}$ and $\mathrm{K}$ associated with non-crystalline reducible phases each only make up about $10 \%$ of total K for both S125 and BG-2 soils. For Ca, the crystalline reducible and residual fractions are quantitatively the most important. In S125 soils, these fractions account for 35\% and 31\% of the total Ca extracted in the sequential procedure. A total of $10 \%$ of the total extractable Ca is held by non-crystalline reducible phases, while about $22 \%$ is in exchangeable form. Exchangeable and residual Ca in BG-2 soils each make up about $40 \%$ of the total sequentially extracted $\mathrm{Ca}$ each, while non-crystalline reducible phases account for an additional $12 \%$ of the Ca. The contribution of Ca held by crystalline reducible phases is small (about 6\%) in BG-2 soils.

\subsubsection{Anthropogenic elements}

On average $27 \%$ and $55 \%$ of the total sequentially extracted $\mathrm{Cu}$ in S125 and BG-2 soils is associated with non-crystalline and crystalline reducible phases respectively, whilst about $17 \%$ of the total is residual $\mathrm{Cu}$. Exchangeable $\mathrm{Cu}$ has negligible concentrations in both soils.

A different behavior is found for $\mathrm{Zn}$, of which the majority of the total is associated with crystalline reducible phases (on average 35\%) in both soils, while $24 \%$ is held by non-crystalline reducible phases. Residual Zn makes up about 30\% of the total for $\mathrm{S} 125$ and BG-2 soils and $7 \%$ of the total is exchangeable $\mathrm{Zn}$.

Phosphorus is found to be mainly distributed among reducible phases in S125 soils. Non-crystalline phases are evidently dominant in holding P, making up about $50 \%$ of the total, whilst P associated with crystalline phases only represents $25 \%$ of the total. Only $19 \%$ of the total is found to be residual P-phases and about $3 \%$ of the total is easily exchangeable P. Phosphorus in BG-2 soils seems to be more or less uniformly distributed among non-crystalline reducible phases and residual phases, accounting for about $38 \%$ of the total each. About $20 \%$ of total P is associated with crystalline reducible phases, while exchangeable P represents less than $1 \%$ of the total.

\subsection{Mineralogical characterization}

\subsubsection{Fourier-transformed infrared spectroscopy}

The FT-IR spectra (Fig. 3) show the feature and off-site soils to be mineralogically different. Soil features show peak patterns characteristic for phosphates with a broad P-O stretching band at $1020 \mathrm{~cm}^{-1}$.

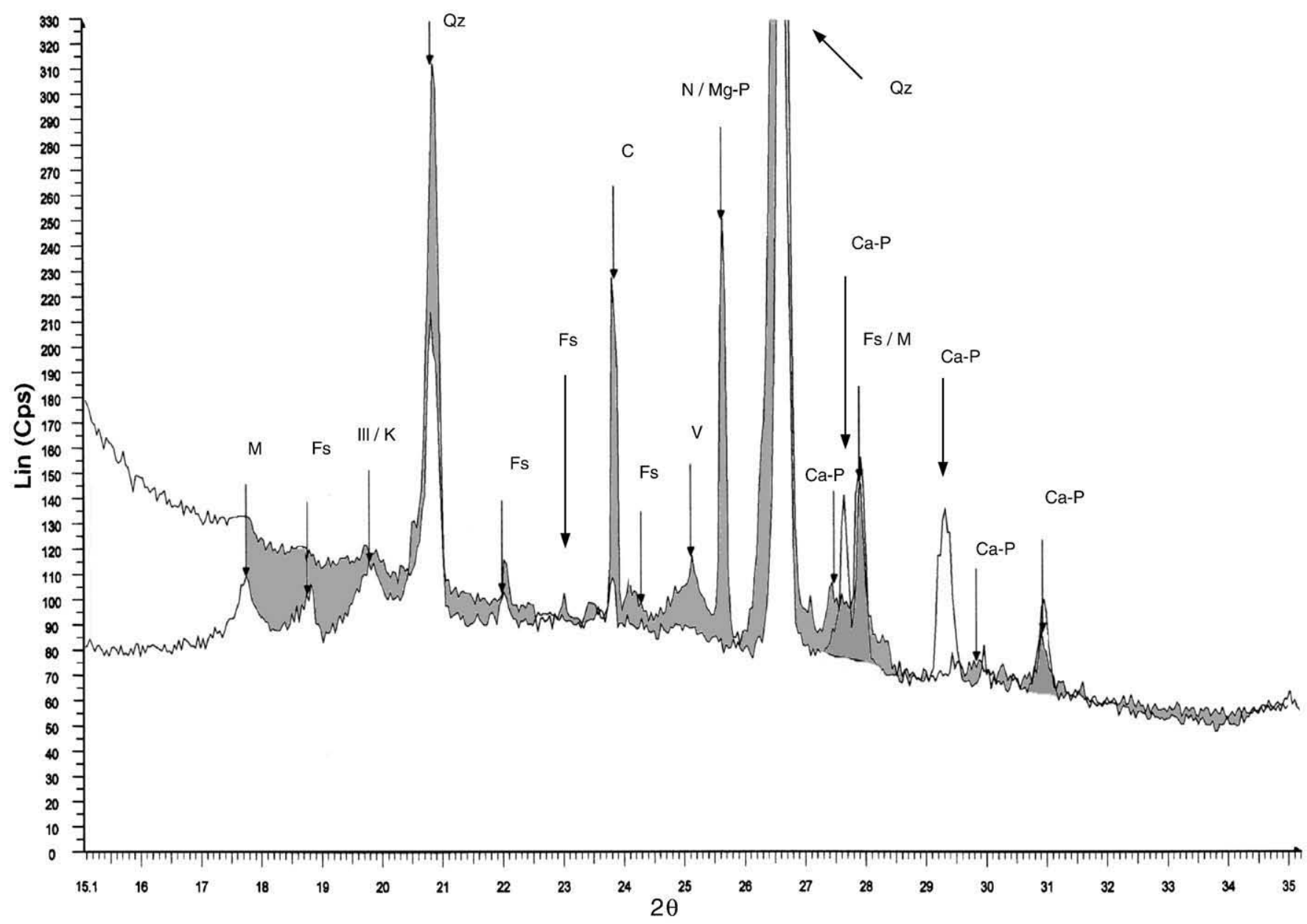

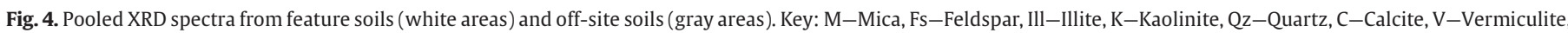
$\mathrm{N}-$ Newberyite, $\mathrm{Mg}-\mathrm{P}-$ Magnesium phosphate mineral forms, $\mathrm{Ca}-\mathrm{P}-$ Calcium phosphate mineral forms. 
The shoulder at about $1030 \mathrm{~cm}^{-1}$ also verifies that this characteristic phosphate stretching mode is present (Lambert et al., 1998). The small shoulder at about $874 \mathrm{~cm}^{-1}$ could be assigned to symmetrical $\mathrm{P}(\mathrm{OH})_{2}$ stretch vibrations of $\left(\mathrm{H}_{2} \mathrm{PO}_{4}\right)^{-}$. This band has, for instance, been observed in FT-IR spectra of strengite $\left(\mathrm{Fe}^{3+} \mathrm{PO}_{4} \cdot 2 \mathrm{H}_{2} \mathrm{O}\right)$ (Farmer, 1974). Further evidence for phosphate minerals in soil features comes from a small shoulder (at about $550 \mathrm{~cm}^{-1}$ ) on the peak near $500 \mathrm{~cm}^{-1}$, which is indicative of O-P-O out-of-plane bend vibrations (Frost, 2004). These vibrations are also represented by peaks at 535 and $472 \mathrm{~cm}^{-1}$ (Farmer, 1974; Frost, 2004). The small peak at $2490 \mathrm{~cm}^{-1}$ can additionally be attributed to $\mathrm{P}-\mathrm{H}$ vibrations. Apart from the latter signal, FT-IR spectra from off-site soils show no evident phosphate bands. The FT-IR spectra of the soil features are also characterized by the presence of bands at 1426,700 and $500 \mathrm{~cm}^{-1}$, assigned to $\mathrm{C}-\mathrm{O}$ vibrations in carbonates (Frost, 2004). In the spectra from off-site soils, these bands are less prominent. Additional signals that appear in both feature and off-site spectra closely resemble $\mathrm{Si}-\mathrm{O}$ vibrations from quartz $\left(\mathrm{SiO}_{2}\right)$ or clays. For instance, the bands at 795, 778 and 690 can be assigned to $\delta(\mathrm{Si}-\mathrm{O})$ vibrations (Farmer, 1974). Asymmetric Si-O-Si stretch vibrations from quartz are apparent from the broad band between 1100 and $1000 \mathrm{~cm}^{-1}$. The presence of organic material in the studied soils is shown by bands in the $3400-3600 \mathrm{~cm}^{-1}$ region, representing $\mathrm{O}-\mathrm{H}$ stretching and $\mathrm{N}-\mathrm{H}$ vibrations. In general, broad peaks are observed, which is indicative of heterogeneous mineral phases (Tracker, 2004; Hay and Myneni, 2007). Sharp peaks and peak splitting of the Si-O signals, however show high crystallinity for quartz and clay minerals. In general, FT-IR spectra show the different soil features to be mineralogically similar. The FT-IR results addition- ally indicate that BG-1 soils more closely resemble soil features and confirm the elemental analysis.

\subsubsection{X-ray diffraction analysis}

Combined XRD patterns of a selection of samples from features $(n=5)$ and off-site locations $(n=5)$ are presented in Fig. 4. The XRD patterns in general show strong reflections at $d=3.34 \AA$ and $d=4.27 \AA$ both arising from quartz. Smaller signals at $d=4.04,3.86,3.73$ and $3.69 \AA$ are indicative of feldspars and calcite $(d=3.86 \AA)$. Clay minerals are typically represented by reflections at $d=5.00 \AA$ (micas), $4.73 \AA$ (chlorite), $4.49 \AA$ (illite/kaolinite) and $3.54 \AA$ (vermiculite). The strong peak at $3.20 \AA$ could additionally be assigned to feldspars or micas (Bayliss et al., 1986). Fig. 6 also shows an absence or lower intensities of signals at 3.24, 3.22, 3.04, 2.98 and $2.89 \AA$ in diffractograms obtained from off-site soils. According to XRD reference literature (Bayliss et al., 1986) reflections in this region could be assigned to calcium phosphate minerals. In addition, signals coming from quartz $(d=3.34 \AA$ and $d=4.27 \AA$ ) and feldspars $(d=3.73 \AA$ and $d=3.69 \AA$ ) were significantly stronger in the off-site soils compared to soil features. The diffractograms of the off-site soils also show a strong reflection at $d=3.47 \AA$, whilst this reflection is absent in the spectra of the features. This reflection may represent newberyite $\left(\mathrm{MgHPO}_{4}\right) \cdot 3\left(\mathrm{H}_{2} \mathrm{O}\right)$ ) or similar minerals (Bayliss et al., 1986).

\subsubsection{Microprobe analyses}

Detailed element distributions in the studied soils were assessed using elemental Energy Dispersive X-ray (EDX) fluorescence mapping. Element maps of a selection of elements are shown in Fig. 5. The

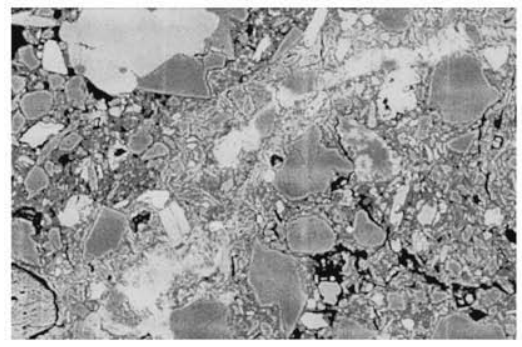

SEM image

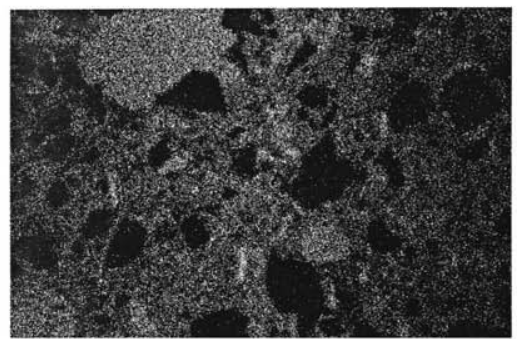

Al

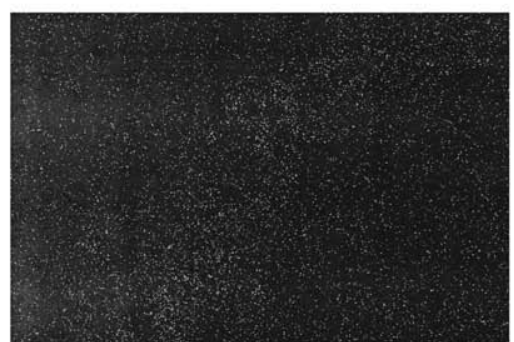

$\mathrm{P}$

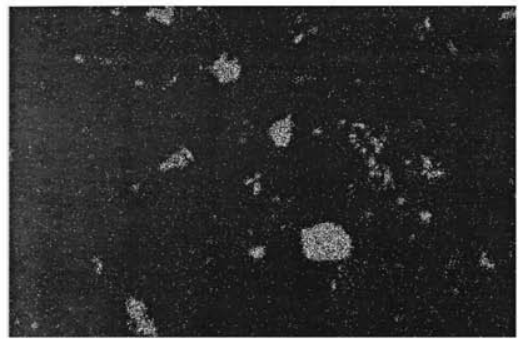

$\mathrm{Na}$

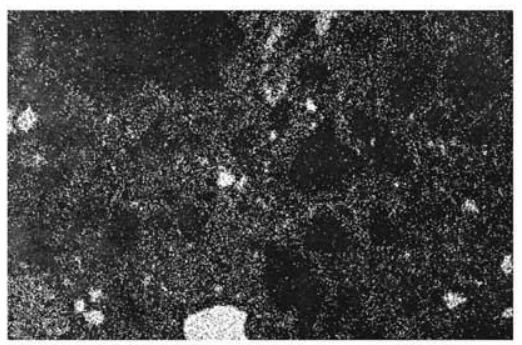

$\mathrm{Mg}$

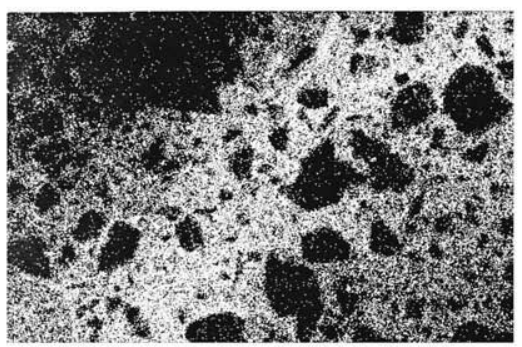

$\mathrm{Fe}$

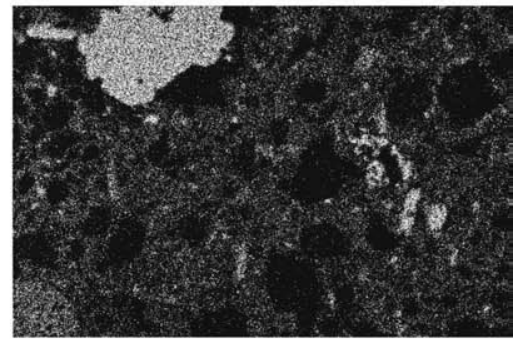

K

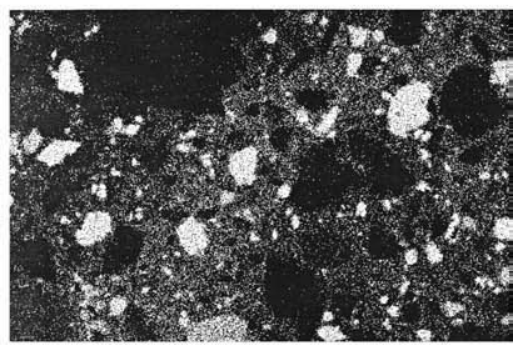

$\mathrm{Ca}$

Fig. 5. EDX element maps of a randomly selected aggregate sample from S125. 
results indicate that, apart from Si-phases (results not shown), Ca, Mg, $\mathrm{K}$ and $\mathrm{Na}$ bearing phases are prominent in soil features. Additionally, the EDX spectra revealed the presence of very small, spatially distributed aggregates containing $\mathrm{Al}$ and $\mathrm{Fe}$ as well. Only very small peaks were observed for phosphorus in the EDX spectra. These results indicate the presence of quartz and clay minerals (Si-phases), calcite and dolomite (Ca- and Mg-phases), Na/K-feldspars (Na-, K-, Al-phases) and $\mathrm{Al} / \mathrm{Fe}$ (oxy)(hydr)oxides (Al and Fe-phases).
To assess the fate of phosphorus in soil features in more detail, aggregate samples from the studied features were studied by means of (electron) microscopy and X-ray elemental analysis (EDX). Greenish aggregates were identified in all samples by light microscopy. Electron microscopy and EDX analysis of these aggregates revealed $\mathrm{Fe}-\mathrm{Ca}-\mathrm{P}$ phases that appeared as coatings on quartz grains and feldspars (Fig. 6). The $\mathrm{P} / \mathrm{Ca}, \mathrm{P} / \mathrm{Fe}$ and $\mathrm{Ca} / \mathrm{Fe}$ ratios were on average $0.89 \pm 0.15,0.28 \pm 0.13$ and $0.32 \pm 0.13$ ( $n=7$ spectra). The stoichiometry of these P-phases
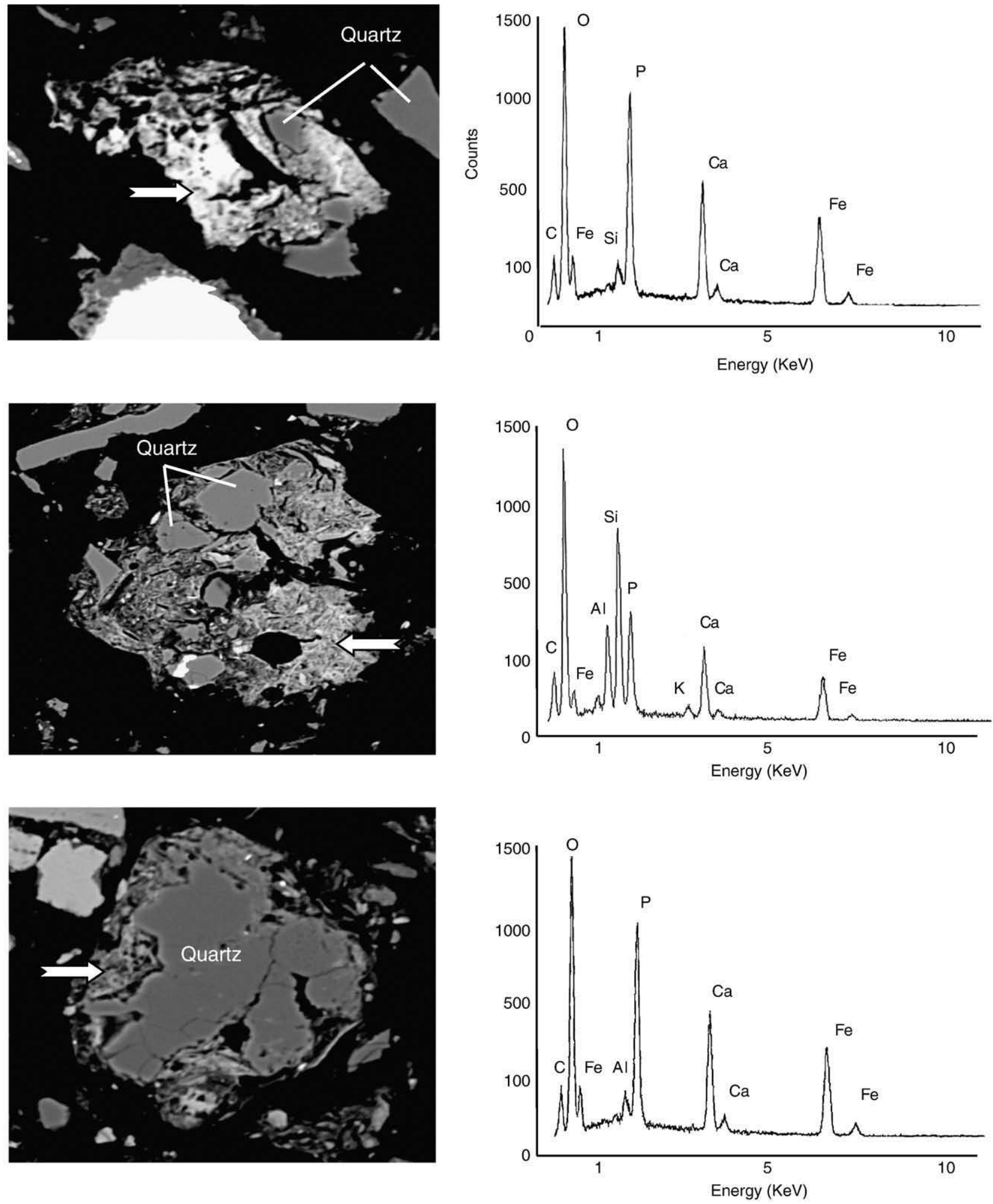

Fig. 6. SEM images and EDX spectra from phosphate phases in aggregate samples from feature S125. The arrows indicate the analyzed areas. 
closely resembles anapaite, mitridatite or similar minerals (Maritan and Mazzoli, 2004). Occasionally, calcite and dolomite precipitates could be identified as well. Mineral phases that contained no or very little phosphorus had relatively high levels of $\mathrm{Si}$ (about 30\%), Al (about 9.5\%) and $\mathrm{K}$ or $\mathrm{Na}$ (about $14 \%$ ).

\section{Discussion}

Chemical analyses indicate that the studied soil features are chemically different from the background soils, particularly with reference to $\mathrm{Ca}, \mathrm{Cu}, \mathrm{P}$ and $\mathrm{Zn}$, and confirm the anthropogenic nature of these features. Geochemical differences between the studied soil features are manifested in $\mathrm{Al}, \mathrm{Fe}$ and Ti levels and most likely reflect natural variation. Average P concentrations on the other hand are equal for most soil features. This implies that chemical analysis can be used to detect these features, but not differentiate between them. Large sample-to-sample P variation within each of the studied features further indicates that P interacts locally with soil constituents.

Phosphorus retention in alkaline calcareous soils is typically controlled by Al- and Fe-(oxy)(hydr)oxides (Ryan et al., 1985; Carreira and Lajtha, 1997; Carreira et al., 2006). Our results confirm this and Pearson correlations between sequentially extracted $\mathrm{P}$ and other studied elements show that $P$ is mainly interacted with non-crystalline Fe-(oxy)(hydr)oxides (Table 2). Low levels of $\mathrm{MgCl}_{2}$ extractable P additionally illustrate that hardly any $\mathrm{P}$ is adsorbed onto the surface of clays or $\mathrm{CaCO}_{3}$ (Ruttenberg, 1992). Resistant inorganic P forms, such as apatite, are largely absent as well, as this is reflected by relatively low levels of $\mathrm{HCl}$ extractable $\mathrm{P}$. The presence of non-crystalline Fe-P phases is unexpected, since crystalline Fe-phases are most abundant in soil features. Also, well-crystallized Fe-P compounds have been reported to dominate P amended soils (Borggaard et al., 2005). An explanation for the non-crystalline Fe-P phases may be periodic dissolution of amorphous metal oxides due to, for example, changes in the water table and subsequent precipitation of P. An analogous mechanism has been suggested for enhanced retention of $\mathrm{P}$ by amorphous Al-oxides (Lookman et al., 1997). Borggaard et al. (2005) additionally suggest that the affinity of amorphous Fe-oxides for P increases with time. The studied off-site soils show a more or less equal distribution of P among the metal oxides. This strongly suggests that Fe and P are more strongly interacted in soil features than in off-site soils.

Pearson correlations (Table 2) also illustrate that non-crystalline Pphases are positively and significantly related to CDB extractable Ca. These results are difficult to interpret, since knowledge of Ca-phases extracted by CDB is limited. It has been reported however that CDB is able to dissolve some Ca-P phases (Pettersson et al., 1988; Jensen et al., 1998).

Results from the FT-IR measurements reveal the presence of phosphate phases in the soil features, but are difficult to interpret since peak patterns closely resemble those of quartz, both appearing in the $1200-450 \mathrm{~cm}^{-1}$ region. The presence of phosphates in our samples is however illustrated by the broad band between about $1020 \mathrm{~cm}^{-1}$ and $1030 \mathrm{~cm}^{-1}$, which is positioned about 70 wavenumbers $\left(\mathrm{cm}^{-1}\right)$ lower than $\mathrm{Si}-\mathrm{O}$ and $\mathrm{Si}-\mathrm{Si}$ bands of quartz, whilst no differences could be observed for the quartz bands in the $700-800 \mathrm{~cm}^{-1}$ region. It is however possible that typical $\mathrm{Si}-\mathrm{Si}$ stretch vibrations in the $1000-1100 \mathrm{~cm}^{-1}$ region are covered up by the broad phosphate peak. Additional information from the FT-IR spectra is obtained from the absence of some specific phosphate signals. It was hence possible to exclude the presence of (hydroxy) apatite, struvite and vivianite which have characteristic vibrations at about $1130 \mathrm{~cm}^{-1}$ (Antonov et al., 1996), $450 \mathrm{~cm}^{-1}$ and $428 \mathrm{~cm}^{-1}$ (Stefov et al., 2004), and about $1300 \mathrm{~cm}^{-1}$ and $1500 \mathrm{~cm}^{-1}$ respectively (McLean et al., 1991).

In comparing the FT-IR spectra of feature samples with off-site soils the following was observed, (a) phosphate and carbonate signals are largely absent in the background spectra, and (b) general peak broadening in the P-O stretch vibration region (1030-1020 $\mathrm{cm}^{-1}$ ) in background spectra. This suggests that not only P-phases in soil features are at least partly of anthropogenic origin, but (Ca)-carbonates as well. The combined presence of phosphates and carbonates in soil features could be linked to livestock-holding practices, because these compounds are both key constituents of manure and urine.

In contrast to the FT-IR data, the XRD spectra clearly display peaks that could be associated with Ca-P phases. True identification of P-minerals in soil features was however difficult, because some peaks in the spectra could be assigned to Ca-P minerals as well as quartz and clay minerals.

Energy dispersive X-ray maps of soil feature samples show that there is no evidence of distinct $P$ enrichments or spatial relationships between $P$ and other elements. These results are consistent with the relatively low concentrations of $\mathrm{P}$ in features and high $\mathrm{P}$ variation (see Fig. 6 and Table 1).

Microprobe surveys of the aggregate samples from soil features allowed identification of widely dispersed $\mathrm{Ca}-\mathrm{Fe}-\mathrm{P}$ phases. The stoichiometry of these phases was obtained from average atomic ratios and revealed the presence of $\mathrm{Ca}_{1.2} \mathrm{Fe}_{3.6}\left(\mathrm{PO}_{4}\right) \mathrm{O}_{3} \cdot \mathrm{H}_{2} \mathrm{O}$. Although the exact stoichiometry of this compound could not be assigned to any known minerals, the structure closely resembles that of mitridatite $\left(\mathrm{Ca}_{2} \mathrm{Fe}^{3+}{ }_{3}\right.$ $\left.\left(\mathrm{PO}_{4}\right)_{3} \mathrm{O}_{2} \cdot 3 \mathrm{H}_{2} \mathrm{O}\right)$ and anapaite $\left(\mathrm{Ca}_{2} \mathrm{Fe}^{2+}\left(\mathrm{PO}_{4}\right)_{2} \cdot 3 \mathrm{H}_{2} \mathrm{O}\right)$. The stoichiometric differences could be attributed to the low abundance of these minerals in our samples, giving the measurements a qualitative character. Stamatakis and Koukouzas (2001) and Medrano and Piper (1997) additionally have reported close intermixing of mitridatite with, for instance, clay minerals, K-feldspar and quartz, which could lead to disturbed stoichiometry as well. Finally, isomorphic substitution may have altered the ideal stoichiometry. Although mitridatite often forms at the expense of anapaite in oxidizing conditions (Nriagu and Dell, 1974), the slow oxidation kinetics of anapaite (Eeckhout et al., 1999) are in favor of both minerals being important in the studied soil features.

\section{Conclusions}

In this study, a chemical and mineralogical survey was conducted to assess the origin and likely formation pathways of greenish soil features in and around an archaeological house plan. All examined soil features could be chemically and mineralogically distinguished from off-site soils. It was, however, not possible to find significant differences between soil features by means of these methods. This suggests that the studied soil features result from more or less

Table 2

Pearson correlations for sequentially extracted $\mathrm{P}$ and $\mathrm{Al}, \mathrm{Fe}$ and $\mathrm{Ca}$

\begin{tabular}{|c|c|c|c|c|c|c|c|c|c|c|c|c|c|}
\hline Extracted phases & CDB-Al & CAB-Al & HCL-Al & Sum-Al & CDB-Fe & $\mathrm{CAB}-\mathrm{Fe}$ & HCL-Fe & Sum-Fe & $\mathrm{MgCl}_{2}-\mathrm{Ca}$ & CDB-Ca & $\mathrm{CAB}-\mathrm{Ca}$ & HCL-Ca & sum-Ca \\
\hline $\mathrm{MgCl}_{2}-\mathrm{P}$ & 0.4 & -0.37 & -0.33 & -0.29 & -0.26 & 0.08 & 0.22 & 0.01 & 0.41 & -0.08 & -0.25 & 0.15 & 0.08 \\
\hline CDB-P & $-.666(*)$ & -0.23 & 0.22 & -0.01 & 0.49 & -0.25 & -0.02 & -0.05 & -0.44 & -0.57 & -0.28 & -0.03 & -0.17 \\
\hline CAB-P & 0 & 0.51 & -0.23 & -0.15 & 0.35 & $.955(* *)$ & -0.25 & $.916(* *)$ & 0.48 & $.783(* *)$ & 0.35 & -0.04 & 0.16 \\
\hline HCL-P & 0.01 & -0.3 & 0.06 & 0.01 & -0.17 & $-.777(* *)$ & -0.01 & $-.738(*)$ & -0.47 & -0.41 & -0.15 & 0.08 & -0.05 \\
\hline Sum-P & -0.18 & 0.44 & -0.18 & -0.17 & 0.49 & $.878(* *)$ & -0.26 & $.893(* *)$ & 0.36 & $.635\left(^{*}\right)$ & 0.27 & -0.04 & 0.12 \\
\hline
\end{tabular}

*Significant at $P<0.05$.

** Significant at $P<0.01$. 
identical inputs. Chemical analysis revealed key anthropogenic elements in the soil features to be $\mathrm{Ca}, \mathrm{Cu}, \mathrm{P}$ and $\mathrm{Zn}$. Focusing on $\mathrm{P}$, sequential extraction experiments showed $\mathrm{P}$ to be mainly associated with amorphous Fe and Ca. Mineralogical analysis furthermore revealed the presence of distinct P-phases, while SEM/EDX analysis showed that $\mathrm{Fe}-\mathrm{Ca}-\mathrm{P}$ coatings, closely resembling mitridatite and anapaite, were present on quartz grains and feldspars. Although the exact pathway of formation of these $\mathrm{Fe}-\mathrm{Ca}-\mathrm{P}$ phases is difficult to assess, the P released from anthropogenic waste may have initially been adsorbed by Fe-oxides. Periodic dissolution of Fe-oxides driven by changing redox conditions and subsequent co-precipitation of $\mathrm{P}$ and Fe with Ca may have led to stable Fe-P-Ca phases, such as anapaite and mitridatite. Since both $\mathrm{P}$ and $\mathrm{Ca}$ are anthropogenic contributors to feature formation and key components of manure and urine, the results suggest that livestock-holding activities may have been responsible for feature formation. An assessment of the source of $\mathrm{Ca}$ and $\mathrm{P}$ in soil features is, however, only possible on a general level, since various activities may have contributed to the input of these elements.

All in all, the combined use of sequential extractions, multi-element analysis and mineralogical methods has allowed a means of studying, in detail, domestic archaeological soil features and holds great promise for site interpretation and possibly archaeological prospection purposes. The applicability of these methods in terms of time and cost effectiveness, however, has yet to be assessed.

\section{Acknowledgments}

We wish to thank the following for their assistance in the analytical work: Helen de Waard (Utrecht University; ICP-OES and XRF analyses), Jan Drenth (NITG-TNO; XRF sample preparation), Tilly Bouten (Utrecht University; microprobe analyses), Wiebke Lohstroh (VU University Amsterdam; XRD analyses) and Rob Smitz (VU University Amsterdam; FT-IR analyses). The Netherlands Organization for Scientific Research (NWO) financially supported this research through the BBO program.

\section{References}

Antonov, E.N., Bagratashvili, V.N., Popov, V.K., Sobol, E.N., Howdle, S.M., 1996. Determination of the stability of laser deposited apatite coatings in phosphate buffered saline solution using Fourier transform infrared (FTIR) spectroscopy. Spectrochimica Acta Part A: Molecular and Biomolecular Spectroscopy 52 (1), 123-127.

Bayliss, P., Erd, D.C., Mrose, M.E., Sabina, A.P., Smith, D.K., 1986. Mineral powder diffraction file. I. Data book. II. Search Manual, JCPDS International Center for Diffraction Data. (Swarthmore PA, USA).

Borggaard, O.K., Raben-Lange, B., Gimsing, A.L., Strobel, B.W., 2005. Influence of humic substances on phosphate adsorption by aluminium and iron oxides. Geoderma 127 (3-4), 270-279.

Carreira, J.A., Lajtha, K.L., 1997. Factors affecting phosphate sorption along a Mediterranean, dolomitic soil and vegetation chronosequence. European Journal of Soil Science $48,139-149$

Carreira, J.A., Viñegla, B., Lajtha, K.L., 2006. Secondary CaCO3 and precipitation of P-Ca compounds control the retention of soil $\mathrm{P}$ in arid ecosystems. Journal of Arid Environments 64 (3), 460-473.

Christensen, T.H., Kjeldsen, P., Bjerg, P.L., Jensen, D.L., Christensen, J.B., Baun, A., Albrechtsen, H., Heron, G., 2001. Biogeochemistry of landfill leachate plumes. Applied Geochemistry 16 (7-8), 659-718.

Cook, S.R., Clarke, A.S., Fulford, M.G., 2005. Soil geochemistry and detection of early Roman precious metal and copper alloy working at the Roman town of Calleva Atrebatum (Silchester, Hampshire, UK). Journal of Archaeological Science 32 (5), 805-812.

Dekker, L.W., de Weerd, M.D., 1973. The value of soil survey for archaeology. Geoderma $10(1-2), 169-178$.

Eeckhout, S.G., De Grave, E., Vochten, R., Blaton, N.M., 1999. Mössbauer effect study of anapaite, $\mathrm{Ca}_{2} \mathrm{Fe}^{2+}\left(\mathrm{PO}_{4}\right)_{2} \cdot 4 \mathrm{H}_{2} \mathrm{O}$, and of its oxidation products. Physics and Chemistry of Minerals 26, 506-512.

Farmer, V.C., 1974. Mineralogical Society Monograph 4. The Infrared Spectra of Minerals. Mineralogical Society, London.

Fontes, M.P.F., Weed, S.B., 1996. Phosphate adsorption by clays from Brazilian Oxisols: relationships with specific surface area and mineralogy. Geoderma 72 (1-2), 37-51.

Fortin, D., Leppard, G.G., Tessier, A., 1993. Characteristics of lacustrine diagenetic iron oxyhydroxides. Geochimica et Cosmochimica Acta 57 (18), 4391-4404.
Frost, R.L., 2004. An infrared and Raman spectroscopic study of natural zinc phosphates. Spectrochimica Acta, Part A: Molecular and Biomolecular Spectroscopy 60A (7), 1439-1445.

Gong, C., Donahoe, R.J., 1997. An experimental study of heavy metal attenuation and mobility in sandy loam soils. Applied Geochemistry 12 (3), 243-254.

Griffith, M.A., 1981. A pedological investigation of an archaeological site in Ontario, Canada, II. Use of chemical data to discriminate features of the benson site. Geoderma 25 (1-2), 27-34.

Hay, M.B., Myneni, S.C.B., 2007. Structural environments of carboxyl groups in natural organic molecules from terrestrial systems. Part 1: infrared spectroscopy. Geochimica et Cosmochimica Acta 71, 3518-3532.

Heeren, S., 2006. Opgravingen bij Tiel-Passewaaij 1, De nederzetting aan de Passewaaijse Hogeweg. Zuidnederlandse Archeologische Rapporten 29.

Hessing, W.A.M., Steenbeek, R., 1992. Landscape and habitation history of 'De Horden' at Wijk bij Duurstede: an Overview. Berichten van de rijksdienst voor oudheidkundig bodemonderszoek 40 .

Huisman, D.J., 2006. How Redox-induced Soil Colour Masks Archaeological Soil Features. Two Cases from the Fluvial Area of the Netherlands, Berichten van de rijksdienst voor oudheidkundig bodemonderszoek 46.

Hyacinthe, C., Van Cappellen, P., 2004. An authigenic iron phosphate phase in estuarine sediments: composition, formation and chemical reactivity. Marine Chemistry 91 (1-4), 227-251.

Jensen, M.B., Hansen, H.C.B., Hansen, S., Jorgensen, P.R., 1998. Phosphate and tritium transport through undisturbed subsoil as affected by ionic strength. Journal of Environmental Quality 27, 139-145.

Knudson, K.J., Frink, L., Hoffman, B.W., Price, T.D., 2004. Chemical characterization of Arctic soils: activity area analysis in contemporary Yup'ik fish camps using ICP-AES Journal of Archaeological Science 31 (4), 443-456.

Kooijmans, L.P., van den Broeke, P.W., Fokkens, H., van Gijn, A., 2005. Nederland in de prehistorie. Uitgeverij Bert Bakker, Amsterdam.

Lambert, J.B., Shurvell, H.F., Lightnes, D.A., Cooks, R.G., 1998. Organic Structural Spec troscopy. Prentice-Hall Inc, New Jersey, US.

Larsen, O., Postma, D., 2001. Kinetics of reductive bulk dissolution of lepidocrocite ferrihydrite, and goethite. Geochimica et Cosmochimica Acta 65 (9), 1367-1379.

Loch, J.P.G., Lagas, P., Haring, B.J.A.M., 1981. Behaviour of heavy metals in soil beneath a landfill; results of model experiments. The Science of The Total Environment 21, 203-213.

Lookman, R., Grobet, P., Merckx, R., van Riemsdijk, W.H., 1997. Application of ${ }^{31} \mathrm{P}$ and ${ }^{27} \mathrm{~A}$ MAS NMR for phosphate speciation studies in soil and aluminium hydroxides: promises and constraints. Geoderma 80, 369-388.

Maritan, L., Mazzoli, C., 2004. Phosphates in archaeological finds: implications for environmental conditions of burial. Archaeometry 46 (4), 673-683.

McLean, R.J.C., Downey, J., Clapham, L., Wilson, J.w.L., Nickel, J.C., 1991. Pyrophosphate inhibition of Proteus mirabilis-induced struvite crystallization in vitro. Clinica Chimica Acta 200 (2-3), 107-117.

Medrano, M.D., Piper, D.Z., 1997. Fe-Ca-phosphate, Fe-silicate, and Mn-oxide minerals in concretions from the Monterey Formation. Chemical Geology 138 (1-2), 9-23.

Middleton, W.D., Price, D.T., 1996. Identification of activity areas by multi-element characterization of sediments from modern and archaeological house floors using inductively coupled plasma-atomic emission spectroscopy. Journal of Archaeological Science 23 (5), 673-687.

Nriagu, J.O., Dell, C.I., 1974. Diagenetic formation of iron phosphates in recent lake sediments. American Mineralogist 59, 934-946.

Parkman, R.H., Curtis, C.D., Vaughan, d.J., Charnock, J.M., 1996. Metal fixation and mobilisation in the sediments of the Afon Goch estuary - Dulas Bay, Anglesey Applied Geochemistry 11 (1-2), 203-210.

Parnell, J.J., Terry, R.E., Nelson, Z., 2002. Soil chemical analysis applied as an interpretive too for ancient human activities in Piedras Negras, Guatemala. Journal of Archaeological Science 29 (4), 379-404.

Pettersson, K., Boström, B., Jacobsen, O.S., 1988. Phosphorus in sediments - speciation and analysis. Hydrobiologia 170, 91-101.

Renfrew, C., Bahn, P., 1991. Archaeology. Theory, Methods and Practice. Thames and Hudson, London.

Ruttenberg, K.C., 1992. Development of a sequential extraction method for different forms of phosphorus in marine sediments. Limnology and oceanography 37 (7) 1460-1482.

Ryan, J., Curtin, D., Cheema, M.A., 1985. Significance of iron oxides and calcium carbonate particle size in phosphorus sorption by calcareous soils. Soil Science Society of America Journal 49, 74-76.

Slomp, C.P., Van der Gaast, S.J., Van Raaphorst, W., 1996. Phosphorus binding by poorly crystalline iron oxides in North Sea sediments. Marine Chemistry 52 (1), 55-73.

Stamatakis, M.G., Koukouzas, N.K., 2001. The occurrence of phosphate minerals in lacustrine clayey diatomite deposits, Thessaly, Central Greece. Sedimentary Geology 139 (1), 33-47.

Steenbeek, R., 1983. Some aspects of the phosphate investigations at the excavation 'De Horden' (Wijk bij Duurstede, the Netherlands). Berichten van de rijksdienst voor oudheidkundig bodemonderszoek 33.

Steenbeek, R. 1984. Een fosfaatkartering in het Kromme Rijngebied. In: van Es, W.A Hessing, W.A.M. (Eds.), Romeinen, Friezen en Franken in het hart van Nederland; van Trajectum tot Dorestad 50 v. C. - 900 n. C., Rijksdienst voor oudheidkundig bodemonderzoek (internal paper), Amersfoort.

Stefov, V., Soptrajanov, B., Spirovski, F., Kuzmanovski, I., Lutz, H.D., Engelen, B., 2004. Infrared and Raman spectra of magnesium ammonium phosphate hexahydrate (struvite) and its isomorphous analogues. I. Spectra of protiated and partially deuterated magnesium potassium phosphate hexahydrate. Journal of Molecular Structure $689(1-2), 1-10$. 
Stipp, S.L.S., Hansen, M., Kristensen, R., Hochella, M.F., Bennedsen, L., Dideriksen, K, Balic- Zunic, T., Leonard, D., Mathieu, H.-J., 2002. Behaviour of Fe-oxides relevant to contaminant uptake in the environment. Chemical Geology 190 (1-4), 321-337.

Sugita, R., Marumo, Y., 1996. Validity of color examination for forensic soil identification. Forensic Science International 83 (3), 201-210.

Sullivan, K.A., Kealhofer, L., 2004. Identifying activity areas in archaeological soils from a colonial Virginia house lot using phytolith analysis and soil chemistry. Journal of Archaeological Science 31 (12), 1659-1673.

Terry, R.E., Fernandez, F.G., Parnell, J.J., Inomata, T., 2004. The story in the floors: chemical signatures of ancient and modern Maya activities at Aguateca, Guatemala. Journal of Archaeological Science 31 (9), 1237-1250.

Tessier, A., Fortin, D., Belzile, N., DeVitre, R.R., Leppard, G.G., 1996. Metal sorption to diagenetic iron and manganese oxyhydroxides and associated organic matter: narrowing the gap between field and laboratory measurements. Geochimica et Cosmochimica Acta 60 (3), 387-404

Tracker, R.C., 2004. Hydroxyl ordering in igneous apatite. American Mineralogist 89 (10), 1411-1421.

Wells, E.C., 2004. Investigating activity patterns in Prehispanic plazas: weak acidextraction ICP-AES analysis of anthrosols at classic period El Coyote, Northwestern Honduras. Archaeometry 46, 67-84.

Wilson, C.A. Davidson, D.A. Cresser, M.S. 2008. Multi-element soil analysis: an assessment of its potential as an aid to archaeological interpretation. Journal of Archaeological Science 35 (2), 412-424. 